\title{
Saving Small Business: The Urgent Need for Improved Business Succession Planning and how Immigrant Entrepreneurs can Help
}

\author{
Sarah V. Wayland
}

\begin{abstract}
Small business is the backbone of the Canadian economy, yet fewer than half of small and medium-sized enterprises (SMEs) in Canada currently have a succession plan in place. As such, many of these businesses could be at risk of closure, potentially reducing the wealth of the business owners in question and depriving communities of needed goods and services. This paper explores the possibility of business succession matching programs, with a focus on immigrants as potential purchasers of businesses. Immigrants are more likely to own a business than their Canadian-born counterparts, and a succession matching program could enable them to access established businesses, mentoring, and even creative financing to enhance their own chances of success as well as preserving desirable firms. The research is based on a review of existing literature, case studies and several interviews which identify an urgent need and potential solutions.
\end{abstract}

Keywords: succession planning, small enterprise, immigration, immigrant entrepreneurs

\section{Introduction}

Defined as firms with fewer than 100 employees, small businesses are important to our provincial and national economies, comprising $98 \%$ of Canadian businesses and accounting for more than two million jobs in Ontario, or $37 \%$ of all private employment in the province (Geobey and Ronson, 2017; Government of Canada, 2016). Based on assumptions drawn from Canada-wide small business owner data in the 2014 Survey on Financing and Growth of Small and Medium Enterprises (SMEs), Geobey and Ronson (2017) estimate that close to 240,000 or $57.7 \%$ of Ontario's small businesses will be changing ownership within the next fifteen years, many of them quite soon as owners have already surpassed retirement age.

Government statistics on business succession are supported by recent survey data. Getting the Transition Right, a Canadian Federation of Independent Business (CFIB) report based on member survey data, found that close to half of SME owners stated their intention to exit their business within five years, similar to levels identified in the previous CFIB survey on this topic in 2012 and dramatic increase from the 2006 survey. Fully $72 \%$ expected to exit their business within ten years (Cruz, 2018; Bruce and Wong, 2012).

According to the 2018 CFIB report, more than 1.5 trillion dollars of business assets could be transferred to the next generation over the next decade, an increase of 50\% from the 2012 
estimate. The most commonly cited reason to exit a business was retirement. More than $80 \%$ of those intending to exit their business stated their intentions to retire (Cruz, 2018).

In the same survey, just over half of business owners admitted that they did not have a succession plan for their business. Given the importance of small business to the Canadian economy and the looming retirements, action is needed to promote a variety of succession planning tools and options.

The cost of doing nothing is high: Canada small businesses employed over 8.2 million individuals, or 70.5\% of Canada's total private sector labour force, in 2015. Small businesses contributed an average of $30 \%$ to the gross domestic product (GDP) to each province in 2014 (Government of Canada, 2016).

Geobey and Ronson (2017) argue that Ontario could lose up to \$100 billion of its GDP in lost productive capacity and up to one million jobs. This would hit rural areas particularly hard, depriving rural areas of access to key goods and services and further contributing talent flight. Another negative outcome would be the lost knowledge and expertise when a business closes, potentially damaging local supply chains, worker productivity and innovative capacity of industry.

This paper explores the possibility of business succession matching programs, with a focus on immigrants as potential purchasers of businesses. The research is based on a review of existing literature, case studies and several interviews.

\section{What is Business Succession Planning?}

The idea of business succession planning is straightforward. It entails the considerations and processes involved in the preparation for the transfer, sale, or closure of a business from its current owner to a successor. The succession can involve a transfer to members of the owner's family, employees, or external buyers. Successful succession results in a continuation of the business, at least in the short term (Ip and Jacobs, 2006).

Today, business owners are living longer and waiting longer to retire, often making it harder to simply pass along a business to a relative (Government of Canada, 2016). Indeed, close to half (48\%) of Canada's small business owners are expecting to sell to someone unrelated to them as their exit plan. Yet at the same time, finding a buyer or suitable successor was identified as the biggest obstacle to selling a business (identified by $56 \%$ of respondents). Valuing the business was identified as a barrier by $48 \%$ of respondents. Agreement on the value of the business is key to a successful transition between seller and buyer (Cruz, 2018).

As simple as the concept may seem, it is the many considerations that must be explored and decided upon as part of the execution that lead to great complexities. It is for these reasons that many business owners never get around to doing succession planning. 
A recent presentation from the Government of Ontario outlines a conceptual framework for understanding succession planning, including positive and negative impacts:

\section{SME Succession Planning Conceptual Framework}

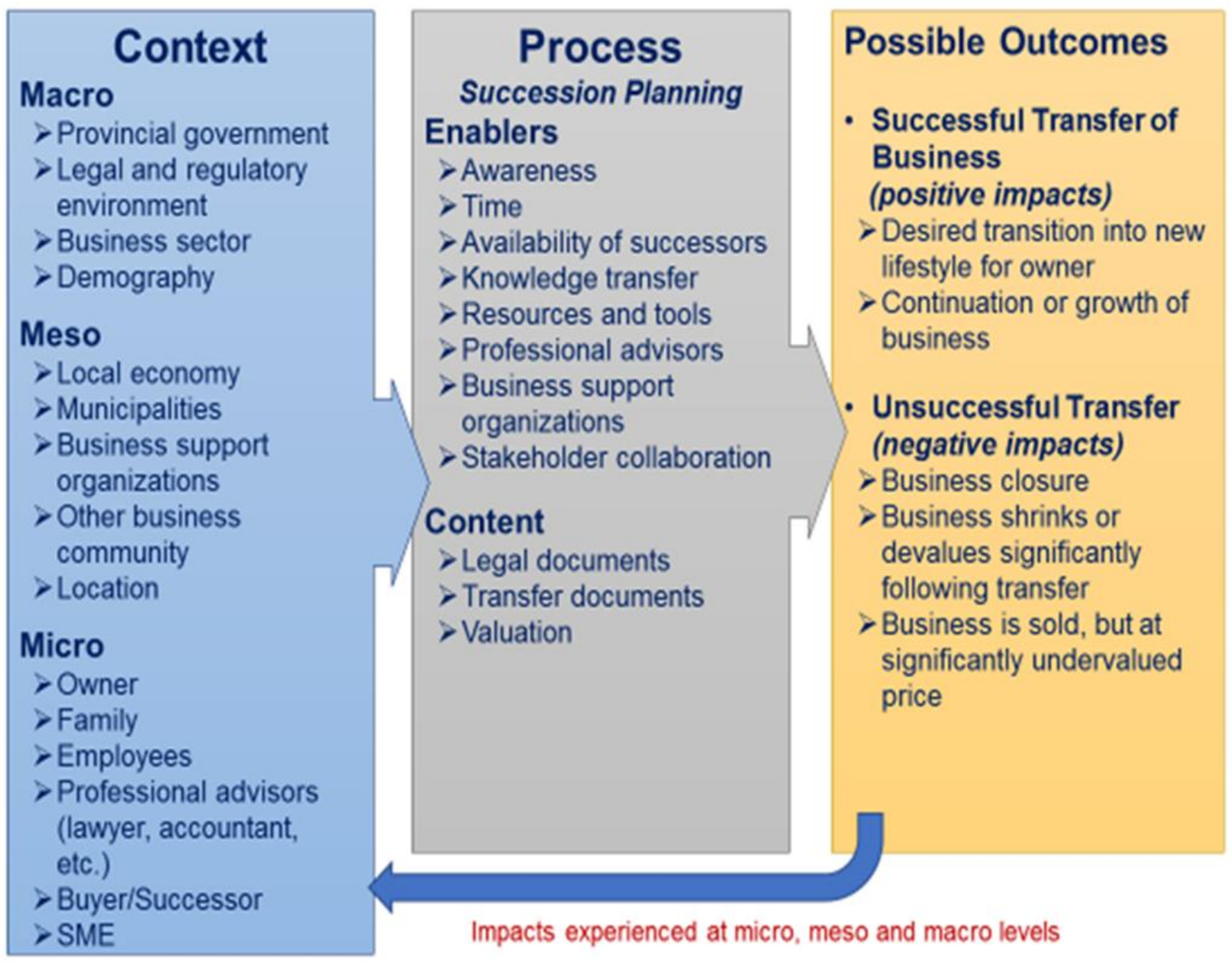

Source: Ontario Ministry of Economic Development and Growth. (2018).

\section{Challenges of Business Succession Planning}

Business succession planning is not always straightforward or simple, and a successful transition entails the alignment of numerous elements. A 2016 study on this topic by the Ontario Ministry of Economic Development and Growth (MEGD) identified numerous major types of challenges to successful succession planning and clustered them into six categories:

- Finding relevant information

- Limited knowledge of succession planning and business transfers

- Finding a successor

- Emotional challenges

- Scope of work of SME support personnel 
- Financial challenges, taxation, legal and legislative/regulatory restrictions (Ontario MEGD, 2018).

A study of immigrant business owners found them also often unable to find someone to take over their businesses, with many not expecting their children to take over their businesses as they might if they were still in Asia or places where the next generation is groomed to take over. It was felt that Canada lacked a culture of succession planning because there are so many opportunities for youth to pursue, and that Canada's education system gives them independent minds. Some felt that their children lacked the work ethic or drive (Momani, 2016). Some owners interviewed for the same study felt that going public was not a viable option because their type of enterprise had low barriers to entry. They felt that investors would not buy into a business that they might be able to replicate themselves (Momani, 2016).

Any robust succession planning program would need to address as many of the above challenges as possible. Success factors for a business succession immigration program include a system for matching sellers with buyers, a transparent and fair business valuation process, and financing options for prospective buyers. One potential policy identified in the Ontario Government study, was to create a service for emergent entrepreneurs to access information on existing SME's whose owners are planning to retire (Ontario MEDG, 2018)

In brief, business succession is a challenge in dire need of a solution. This paper proposes immigration matching as one potential solution, possibly as part of a broader provinciallyendorsed business succession plan.

\section{Immigration \& Business Ownership}

Immigration is an ongoing part of Canada's strategy to grow its population and labour force. Immigrants settle in large urban areas, have difficulty in the labour market, and often work below their skill levels. Immigrants are also slightly more likely to own a business compared to the Canadian-born population, and they often arrive in Canada with some capital that could be used to invest in a business. On the downside, immigrants often lack professional and business networks outside of their own communities and lack knowledge of Canadian rules and regulations surrounding business ownership (Wayland, 2012).

Many newcomers and skilled immigrants migrate to Canada looking for economic opportunities - including business ownership -- and a place to call home. They want the same things for themselves and their families as Canadians do, and they are more mobile in their pursuits. By definition, economic immigrants possess education and skills, and they often immigrate to Canada with cash reserves.

Interestingly, the 2018 edition of the CFIB survey report makes mention of immigrants as a possible source of business procurement for the first time. Under recommendations for governments, the report states: "Consider creating a business succession immigration stream that 
allows potential immigrants to purchase and operate an existing business in Canada" (Cruz, 2018). Previous editions of the survey report did not make any mention of immigrants.

This is an urgent issue in need of a creative solution. Many immigrants to Canada do have business experience, but supports would be needed for effective business transition.

\section{Key Ingredients for a Successful Matching Program}

Based on a review of the literature, several key ingredients for a successful program can be identified. The suggestions below are largely adopted from a recent study in this area by the Ottawa Community Loan Fund and Ottawa Employment Hub (2018). Briefly, they are as follows:

- Finding a balance between maintaining anonymity of the sellers and being able to showcase the business for sale to potential purchasers.

- A commitment of at least three years to get the program off the ground. Sources other than government funding are preferred and could support more sustainable programs. This may involve some user fees on a cost-recovery basis. It is important to 'plant the seeds' to get both sides - buyer and seller - thinking.

- Municipality or matching agent must protect themselves legally; most see themselves as 'connectors.' Normally the valuation, takeover process, is left to external professionals.

- Presence of an advisory team. In the case of immigrant succession programs, having a strong, diverse advisory team is especially useful.

- Having a list of potential sources for financing, such as Futurpreneur, Business Development Bank of Canada, credit unions, and Community Futures.

- Incorporate a mentorship component into the program, with mentors who are actual entrepreneurs.

- Incorporate education sessions for buyers and sellers into the program:

- For buyers, the big three topics are accounting, banking and law, as well as 'Business 101'

- Also: financial literacy, management, human resources, social media, marketing, Workplace Safety and Insurance Board, employer regulations, Canada Business Network, municipal bylaws

- Do not facilitate matches too quickly. Buyers and sellers should be prepped as above before meeting to discuss sales.

- A period of collaborative management seen as best practice and strongly recommended as part of the takeover process 


\section{Case Studies}

The idea of business succession focused on immigrants is not necessarily new, but there are very limited Canadian examples of programs in this area. This research was able to identify only two cases, each of which is described in this section.

In addition to these two examples from Atlantic Canada, an Ontario-based pilot project called the Ontario Immigrant Network operated from approximately 2012 to 2014 in southwestern Ontario. This project attempted to attract immigrants from the Greater Toronto Area to buy businesses in smaller communities in southwestern Ontario. Unfortunately, no publicly available results of this pilot could be found.

\section{Succession Connect - Fredericton, New Brunswick}

In October 2016, The Fredericton Chamber of Commerce launched an innovative pilot project matching immigrants to existing business opportunities. Succession Connect was created with the goal of serving two populations: current business owners nearing retirement or otherwise trying to sell their business and immigrant investors seeking to purchase turnkey operations. The project was launched in the hopes that facilitating these connections within the region would enable businesses to continue beyond first generation ownership, thereby preserving jobs and the related economic impact on the community. This pilot program was the first of its kind in Canada, and received funding from Atlantic Canada Opportunities Agency, Government of New Brunswick and City of Fredericton in addition to a variety of valued corporate sponsors that support the program.

From the outset, the program had a three year mandate with proposed goals and outcomes for each year of the mandate. The deliverables have encompassed the development of a client onboarding process, the investment in customer relationship management (CRM) software and the creation of educational resources and supports geared to business immigrants that intend to purchase a business. In addition to building out the program infrastructure, the program continues to build a current database of buyer and seller leads that are used within the matching process.

Succession planning involves sensitive information. In Succession Connect, the Chamber is making the connection, but it is not a broker. The Chamber partnered with McInnes Cooper Law to create the necessary liability waivers and non-disclosure agreements. At the first meeting, clients must agree to liability terms before entering into the program. After the connection is made between the current business owner and potential successor, it is then up to the two parties to take the next steps in the due diligence process. The Succession Specialist facilitates the warm introduction between both parties but does not remain heavily involved in discussions and negotiations from that point. Succession Connect expresses to clients the importance of professional support throughout the process and will connect newcomers with their trusted 
network of accountants, lawyers and financial institutions as required throughout the process. All costs for professional services remain the responsibility of the respective buyer and seller parties.

Most of the clients in the program are investors entering Canada through New Brunswick's Provincial Nominee Program (PNP) entrepreneur stream. Succession Connect collects information from the prospective businesses to determine if the opportunities may align with the PNP guidelines which require an investment of at least $\$ 250,000$ and profitability in the previous several years. Investors also must take an active management role in the business as opposed to a passive investment. It is important to note that while Succession Connect collects available information about businesses that are seeking to transition, the Provincial Government of New Brunswick ultimately determines if the business proposal will be approved by the PNP program. Additionally, Succession Connect will assist other immigrants that may be entering into the province through other streams of immigration and therefore are not limited to the constraints of the PNP entrepreneurial stream guidelines.

There has been strong local reception to the program, both from business owners and newcomers. As of January 2019, the program has been in a fully operational mode for approximately six months and is within weeks of completing its product development components, including a written guide, video series and workshop curriculum geared to immigrants that are settling in the area and seeking to purchase existing businesses. Several business matches are currently in the negotiation and exploration phase (Crowe, personal communication, 2019).

The program has gained regional attention and the interest of other municipalities in New Brunswick that are exploring the possibility of expanding the program to their regions (Crowe, personal communication, 2019). The Conference Board of Canada has recommended that the Succession Connect program be considered by the federal immigration department to be recommended to all provinces and all major centres (Letson, 2017).

Although still in the pilot phase, there have already been some lessons learned from the program. First, allow the necessary time to build effective tools and resources. Ensure sufficient engagement within the business community to build critical mass within the database that will ultimately result in more successful matches. For Succession Connect, lead generation continues to be an essential component of the program's success. Third, it is advantageous to co-locate the program office with other business immigrant related programs. In Fredericton, it is housed within the Chamber of Commerce's HIVE startup incubator and Business Immigrant Mentorship Program. This incubator is also conveniently located within Planet Hatch, which is considered to be the business startup hub of Fredericton. The partnership between Ignite Fredericton and the Fredericton Chamber of Commerce is a critical component to the program's ability to offer a full suite of business support services for newcomers that are seeking to create a successful life as an entrepreneur in Canada. Finally, the project team sees value in the personal touch and confidentiality that would not be possible in a tool that depends strictly on online matching. 
Particularly in a program aimed at newcomers to Canada, clients may require more in-depth support than is available online.

Almost three years into development, Succession Connect is the most promising example of a Canadian program to address business succession.

\section{Nova Scotia business mentorship program}

In considering lessons learned from various iterations of similar programs, it is important to consider programs with problematic execution as well as stellar programs. Lessons can be learned from the mistakes of past programs, for example the Nova Scotia business mentorship program, which -although not a business succession program exactly - contained many of the same elements.

Launched by the province of Nova Scotia in 2002, the business mentorship program was developed to take advantage of the new provincial nominee program. The program was created to increase investment and create high-value jobs by attracting wealthy and skilled immigrants to the province.

The program was created to match nominees with a business of their choice, initially charging participants $\$ 130,500$. This amount included a requirement to pay the nominee's own salary of $\$ 20,000$ for a six month period, and $\$ 80,000$ went to the mentoring business. According to the Office of the Auditor General, $\$ 30,000$ was paid to the provincial government and to the firm hired to run the program (McDonough, 2008).

Approximately 806 newcomers paid the fees, but only 200 persons participated in mentorships. The rest were unable to find suitable mentorships within the one-year timeframe. According to McDonough's analysis, even among the participants, "many were either placed in inappropriate positions that did not reflect their skills and/or education and many reported not being placed into positions that reflected the program's entry-level management requirement" (2008). As an example, an Iranian plastic surgeon, in desperation, found a position working on computers at a car dealership (McDonough, 2008).

According to McDonough, the program failed to create an environment conducive to the economic integration of newcomers, nor did it facilitate job creation. After six months, each 'mentorship' was over, a local business had gained \$80,000. Participants had secured permanent residency status, but "with little to no long term socio-economic investment or employment opportunity in Nova Scotia" (McDonough, 2008). In effect, the program helped newcomers fund existing businesses but offered little long-term benefit for the immigrants themselves. Unfortunately, analysis indicates that Nova Scotia lacked the socio-economic conditions necessary to achieve desired outcomes (McDonough, 2008). The program was not only ineffective, but resulted in a public scandal that included refunding money to applicants (McDonough, 2008). Participants of the business mentorship program did not have a permanent 
position in the management and operations of the mentor businesses, nor were they financial partners.

A number of lessons can be gleaned from the results of this pilot project. First, think through and test every step, perhaps with mock investors or archetypes of potential investors. Second, offering financial incentives to participating business owners may attract people only interested in the money rather than helping a newcomer. Finally, programs should work to screen out buyers hoping to 'buy a job' but who are not really interested in or prepared for entrepreneurship.

\section{Proposal for a National Business Succession Immigration Program}

The above case studies offer examples of promising practices as well as pitfalls to avoid in designing any business succession program. A review of the literature also located a proposal for a provincial or federal program that incorporates some of the above learnings and is rooted in the alarming need for succession planning identified by the Canadian Federation of Independent Business (CFIB). This proposal was featured in a recent publication from the Conference Board of Canada (El Assal, 2017).

The CFIB proposes a that a national succession matching program be modelled on the Express Entry application management processing system used for economic immigrants to Canada since 2015. Under Express Entry, candidates must reach a set amount of points in order to be invited to apply for immigration. According to Pohlmann of the CFIB, 'an effective business valuation process would ease transactions and ... immigrants should have access to financing to complement the assets they must bring with them to Canada' (El Assal, 2017).

Many of the proposed criteria are similar to the terminated federal Entrepreneur Program, though Pohlmann noted her proposal is meant to start discussion on the program's ultimate shape. Her proposal is as follows:

Selection Criteria Applicants would be required to meet the following criteria:

- have at least three years' experience as an active business owner, senior manager, or a combination of both;

- $\quad$ have a minimum net worth of $\$ 250,000$;

- invest a minimum of $\$ 100,000$;

- commit to purchasing at least one-third of the business and residing within the business's province;

- $\quad$ be between the ages of 21 and 59 .

Language proficiency would not be mandatory. Applicants might also be required to do the following:

- actively manage daily operations of the business; 
- demonstrate the business's commercial viability;

- ensure the business provides at least one FTE job for a resident of Canada;

- commit to keeping existing employees for a certain length of time;

- provide a purchase and sale agreement that includes key information, such as price, timelines, a description of the business, and plans for upgrades.

At the event where this plan was presented, participants expressed support for a federal succession-planning program but expressed their beliefs that program effectiveness would be contingent on addressing some issues. Some participants suggested that applicant points should be contingent on their experience in the field. Those looking to purchase a business in a field where they already had experience would receive more points, and vice versa. It was also suggested that program designers draw upon the expertise of private sector financial intermediaries in addition to the small number of publicly-funded initiatives in this area (El Assal, 2017).

\section{Importance of the Economic and Social Health of the Broader Community}

A business succession program focused on immigrants holds much promise. The logic is sound: many business owners are set to retire, and many immigrants come to Canada looking for opportunities and often are challenged to find work in their fields of expertise. Many also come with business experience.

However, some caution is in order. Communities in economic decline cannot effectively turn to immigration as a quick fix to their situations. Ongoing investments in the Atlantic provinces to stem demographic decline have illustrated the absence of quick turnarounds. Regional immigration to second-tier cities will only be successful if economic opportunities are accompanied by the presence of a welcoming community, including settlement services (McIsaac, 2003). This can be achieved in smaller, even rural communities - as evidenced in Winkler, Manitoba for example - but requires partnerships among key stakeholders, including business, government, not for profits, and faith communities.

In sum, although this review of literature and programs in this area finds great merit with the idea of business succession programming focused on immigrant purchasers, it is unrealistic to expect immigrants to want to live in communities that face challenges retaining their own Canadianborn populations. An ideal localation for most immigrants would include broader educational and economic opportunities, presence of a robust immigrant community, and access to places of worship and ethnic groceries. Piloting a succession program in a growing community with an existing immigrant population base and proximity to a broader metropolis would provide a more robust test of what a successful program might look like. 


\section{Conclusion}

This paper has provided an overview of the urgent need for better business succession planning in Canada and pointed to immigration-focused matching programs as a potential solution. In the course of this research, only one seemingly successful immigrant-focused program was found, and it is still in the pilot stage.

Although such programs have great potential to help the economy, particularly in smaller communities and rural areas where business closure can more adversely affect local quality of life (e.g., closure of a community's only bakery or coffee shop), success depends in part on being situated within vibrant economic areas or areas that show real potential for growth.

The need has been identified, yet action thus far has been small-scale and never extended beyond the pilot phase. Creating robust business succession matching programs is a daunting task and does not easily fall to one order of government or institution. It is hoped that this paper will help draw attention to the problem as well as potential solutions, and that further examination and investment into this issue will be forthcoming.

\section{Author biography}

Sarah Wayland is Senior Project Manager for the Hamilton Immigration Partnership Council, located in the City of Hamilton's Economic Development Division. From 2013 to 2018, she was the creator and leader of Global Hamilton, the City of Hamilton's immigrant attraction and retention initiative.

\section{References}

Picard, B. (2006) Making Succession a Success: Perspectives from Canadian Small and Medium-Sized Enterprises. Journal of Small Business Management, 44(2), pp. 306-309

Bruce and Wong. (2012). Passing on Business to the Next Generation: Survey Results on Small Business Succession Planning. CFIB, Research November. http://www.cfib-fcei.ca/cfibdocuments/rr3277.pdf

Cruz, M. (2018). Getting the Transition Right: Survey Results on Small Business Succession Planning. Canadian Federation of Independent Business. https://www.cfibfcei.ca/sites/default/files/2018-11/Getting-the-transition-right-succession-planning-report.pdf

El-Assal, K. (2017). Entrepreneur and Investor Immigration: Creating Jobs and Growth. Ottawa: The Conference Board of Canada.

Geobey and Ronson. (2017). Decent Work through Decent Workplaces: The Co-Operative Opportunity in Ontario Small Business Succession. Prepared for the Atkinson Foundation. $4^{\text {th }}$ draft, November 28. 
Government of Canada. (2016). Key Small Business Statistics, June 2016, Innovation, Science and Economic Development Canada, Small Business Branch. http://www.ic.gc.ca/sbstatistics

Ip and Jacobs. (2006). Business succession planning: a review of the evidence. Journal of Small Business and Enterprise Development,13,3, 326-50.

Letson, C. (2017). Immigrants Could Be Answer for Family Businesses With No Succession Plan. http://huddle.today/pilot-project-out-of-fredericton-to-connect-businesses-with-successors/

McDonough, P. L. (2008), Nova Scotia's Provincial Immigration Policy: The Failure of the Business Mentorship Program." Theses and dissertations. Paper 105. (Ryerson University)

McIsaac, E. (2003). Nation Building Through Cities: A New Deal for Immigrant Settlement in Canada. Ottawa: Caledon Institute of Social Policy. Retrieved August 01, 2008 from: www.triec.ca/docs/NationBuilding.pdf

Momani, B. (2016). New Canadian Entrepreneurs: An Underappreciated Contribution to Canadian Prosperity? www.cigionline.org

Ontario Ministry of Economic Development and Growth. (2018), Study on Succession Planning for SMEs in Ontario, Presentation to the 61st Annual EDCO Conference and Showcase. Toronto, February 5-7, 2018.

Ottawa Community Loan Fund and Ottawa Employment Hub. 2018. ReNEWing Established Businesses OCLF-LEPC Ottawa Research on Business Transitions. Study Findings \& Recommendations for Moving Forward. Submitted to Ontario Trillium Foundation. Published on: January 12, 2018.

Wayland, Sarah. (2012). Winning Strategies for Immigrant Entrepreneurship in Five Communities, Final Project Report. Prepared with assistance from Leah Hamilton, PhD, and Gerald Bierling for Citizenship and Immigration Canada and five Ontario Workforce Planning Boards. Available at: http://workforceplanninghamilton.ca/publications/tag/immigrant 